\title{
Expansão espacial da leishmaniose visceral americana em São Luis, Maranhão, Brasil
}

\author{
Space expansion of the American visceral leishmaniasis \\ in São Luis, Maranhão, Brazil \\ Wellington da Silva Mendes', Antonio Augusto Moura da Silva1, José de Ribamar Trovão', \\ Antônio Rafael da Silva ${ }^{1}$ e Jackson Maurício Lopes Costa ${ }^{1}$
}

\begin{abstract}
Resumo Descreve-se a ocupação espacial no município de São Luis e a expansão da leishmaniose visceral americana(LVA) na mesma. Foram analisadas as fichas de registro de atendimento de casos de leishmaniose visceral da Diretoria Regional da Fundação Nacional de Saúde do Maranhão no período de setembro de 1982 a dezembro de 1996, assim como documentos oficiais sobre a ocupação espacial do município. Foi observado que os casos de LVA ao longo da evolução da epidemia em São Luis apresentaram distribuição espacial e concentração semelhantes a apresentada pelo fluxo migratório na cidade no mesmo período.
\end{abstract}

Palavras-chaves: Leishmaniose visceral. Ocupação. Fluxo migratório.

Abstract The space occupation and the expansion of American visceral leishmaniasis (AVL) were described in the municipality of São Luis, Maranhão, Northeast Brazil. AVL medical notes from the Fundação Nacional de Saúde as well as official documents about the space occupation were analyzed from September 1982 to December 1996. AVL cases were more likely to occur in recently settled suburbs and tended to follow the same spatial pattern observed for land occupations secondary to migratory fluxes.

Key-words: American Visceral leishmaniasis. Migration. City growth.

A associação entre determinados padrões migratórios e a veiculação de doenças infecciosas no Brasil é reconhecida desde o século XVIII quando foi descrita a relação entre movimentos migratórios ligados à cultura do café e o aparecimento dos primeiros casos da doença de Chagas no estado de São Paulo e, mais recentemente os movimentos migratórios ligados à construção de Brasília que se associaram à presença da esquistossomose mansônica ${ }^{29}$.

Algumas destas doenças surgiram a partir do Brasil colônia, trazidas pelos portugueses, como a varíola, a hanseníase e a tuberculose, enquanto outras foram introduzidas pelos escravos africanos, como a esquistossomose mansônica 5 . As populações migrantes ocupam a terra, e por estratégia de sobrevivência realizam modificações ambientais, promovendo a substituição da mata por pequenas lavouras e criações de animais de pequeno porte 1 . Convivem ainda com o difícil acesso à água tratada e à coleta dos dejetos domiciliares o que, segundo Sabroza et al ${ }^{10}$ representam indicadores das condições de receptividade de doenças transmitidas por vetores urbanos, a exemplo da leishmaniose visceral americana (LVA).

O primeiro núcleo de povoamento da cidade de São Luis, a Praia Grande, se formou em 1612 às margens do rio Bacanga, propiciado pela sua localização estratégica ${ }^{4}$. A expansão espacial se fez de forma linear, de tal maneira que São Luis em 1844 demonstrava um crescimento urbano horizontalizado com vetor de crescimento dirigido, principalmente, no sentido Oeste-Leste.

Com o fim do comércio escravagista, a capital passa de mercantil e agrícola para uma economia industrial, tendo o setor têxtil como o principal fator de crescimento econômico. A busca de oportunidade de trabalho, na indústria que emergia, levou ao surgimento do primeiro bairro suburbano de São Luis, o bairro do Anil, formado na imediações da Fábrica do Anil12.

O corredor de crescimento que, até então, partia da Praia Grande e se dirigia de forma linear até o Bairro do Anil ${ }^{10}$ sofreu grande alteração a partir das décadas

1. Departamento de Patologia do Núcleo de Patologia Tropical e Medicina Social da Universidade Federal do Maranhão, São Luis, MA.

Endereço para correspondência: Dr. Wellington da Silva Mendes. R. Mitra n¹1, Quadra 31, Apt ${ }^{\circ} 1402$, Edifício Costa Marina, Renascença II, $65075-770$ São Luis, MA.

Fax: $5598235-7477$

E-mail:w.mendes@elo.com.br.

Recebido para publicação em 3/7/2000. 
de 1960 e 1970, em função da melhoria do sistema viário com a construção de duas pontes sobre o rio Anil, que determinaram o fim da dificuldade de deslocamento no sentido Norte e Nordeste, e a construção da Barragem do Bacanga e do Anel Viário que criaram condições de expansibilidade espacial no sentido Oeste e Sul do município. Com o subseqüente asfaltamento da BR-135, o acesso rodoviário à capital ganhou intensa movimentação. Assim, o contigente migratório para São Luis se intensificou rapidamente, determinando a ocupação do litoral e do centro.

Na década de 1980, São Luis recebeu grande fluxo migratório oriundo em parte do deslocamento de lavradores que fugiam da seca no Piauí e no Ceará, assim como pelo êxodo de famílias que viviam na zona rural do Estado. A implantação do Distrito Industrial no setor Sul do município, ocupando $21,1 \%$ da superfície territorial da Ilha de São Luis, provocou a retirada de mais de 10.000 moradores de 17 povoados, que viviam da agricultura de subsistência e da pesca artesanal ${ }^{8}$. Entre 1980 e 1985, como conseqüência da adoção por parte do Governo do Estado do Maranhão de uma política de incentivos fiscais foi implantado no distrito industrial o Consórcio Alumínio do Maranhão (ALUMAR) e o Programa Grande Carajás controlado pela Companhia Vale do Rio Doce (CVRD) determinando grande incremento no deslocamento de famílias de lavradores que viviam na área do distrito. Estes migrantes ocuparam as áreas próximas ao porto do Itaqui, especialmente as Vilas Mauro Fecury I e Il e o bairro do Anjo da Guarda em cujas imediações surgiram diversos outros bairros ${ }^{12}$. Segundo dados do IBGE sobre a evolução censitária de São Luis a população da cidade cresceu $162 \%$ entre 1970 e $1991^{67}$.

Neste cenário, em 1982, a leishmaniose visceral americana estabeleceu-se como endemo-epidemia em São Luis, levando ao registro de 1089 casos de LVA em 15 anos $^{311 .}$

O presente estudo teve como objetivo descrever a expansão da LVA e a ocupação espacial da cidade de São Luis, pontuando os aspectos em comum, do ponto de vista de distribuição no tempo e no espaço, entre a endemia e o fluxo migratório.

\section{MATERIAL E MÉTODOS}

Método de análise. Foi realizado um estudo descritivo sobre a epidemia de LVA no município de São Luís, entre setembro de 1982 e dezembro de 1996, e a ocupação espacial da cidade neste período. $O$ número e a distribuição dos casos de leishmaniose visceral americana foram obtidos a partir da ficha de registro de atendimento de casos de leishmaniose visceral da Diretoria Regional da Fundação Nacional de Saúde (FUNASA-MA). O nível de agregação destas unidades espaciais foi o endereço registrado nas fichas de notificação. A distribuição da ocupação espacial do município foi obtida a partir dos recenseamentos da Fundação Instituto Brasileiro de Geografia e Estatística (IBGE), dos Anuários Estatísticos e de documentos da Secretaria Estadual de Turismo e Urbanismo (SETURB). Os dois fenômenos observados foram relatados de forma descritivas sem o compromisso de inferir causalidade entre ambos.

Espaço geográfico. A llha de São Luis encontrase localizada no litoral Norte do Estado, na região do golfão maranhense, bacia costeira de São Luis, Costa setentrional do Brasil. A cidade de São Luis (Figura 1), com uma população de 912 mil habitantes, é um dos quatro municípios localizados na ilha. Situa-se na parte nordeste da ilha, de frente para a baía de São Marcos. Constituída pela agressão sucessiva de sedimentos terciários, possui extensão territorial de $518 \mathrm{~km}^{2}$. Encontrando-se na altitude de 25 a $55 \mathrm{~m}$. O clima é tropical úmido e a temperatura média anual é de $27^{\circ} \mathrm{C}$. A precipitação pluviométrica ocorre durante todo o ano, com maior intensidade entre os meses de janeiro a junho, quando atinge $2.084 \mathrm{~mm}^{3}$.

\section{RESULTADOS}

A epidemia de LVA no Maranhão teve início em setembro de 1982 em uma extensão do bairro do Tirirical, que veio a se constituir no bairro de São Cristóvão. Nos meses seguinte novos casos foram notificados nas proximidades do Tirirical, no sentido da rodovia estadual MA-205, especialmente nos bairros do São Bernardo, Coroadinho e Baixo do Turu. A seguir, os novos casos predominaram no sentido norte da llha, em direção ao litoral. A partir de 1984 a doença passou a ser notificada no centro da cidade, de onde se estendia até o bairro do Anjo da Guarda que recebia parte da população que era deslocada da área destinada à CVRD e à ALUMAR.

No período de 1982 a 1986, foram notificados 615 casos em 67 localidades; de 1987 a 1991 foram notificados 41 casos em 25 localidades, enquanto que de 1992 a 1996 foram notificados 419 casos em 87 localidades, sendo que em 49 (56,3\%) destas, nenhum caso de LVA havia sido diagnosticado até então. Os novos casos de LVA se concentraram no sudeste do município, onde novas localidades surgiram entre 1991 e 1994 como áreas receptoras de migrantes, a exemplo de Vila Nova República e Santa Clara.

Observando a evolução da epidemia de LVA em São Luis com base no coeficiente de incidência por 100 mil habitantes (Figura 2) é possível visualizar que a partir de sua eclosão em 1982, a epidemia apresentou nos anos de 1983/84/85 seu maior coeficiente de incidência. A seguir a ocorrência de casos se estabilizou em níveis endêmicos por sete anos, voltando então em 1993 e 1994 a apresentar-se novamente como epidemia. A partir de 1995 diminuiu rapidamente o número de casos os quais se mantiveram em níveis endêmicos até 1996. 


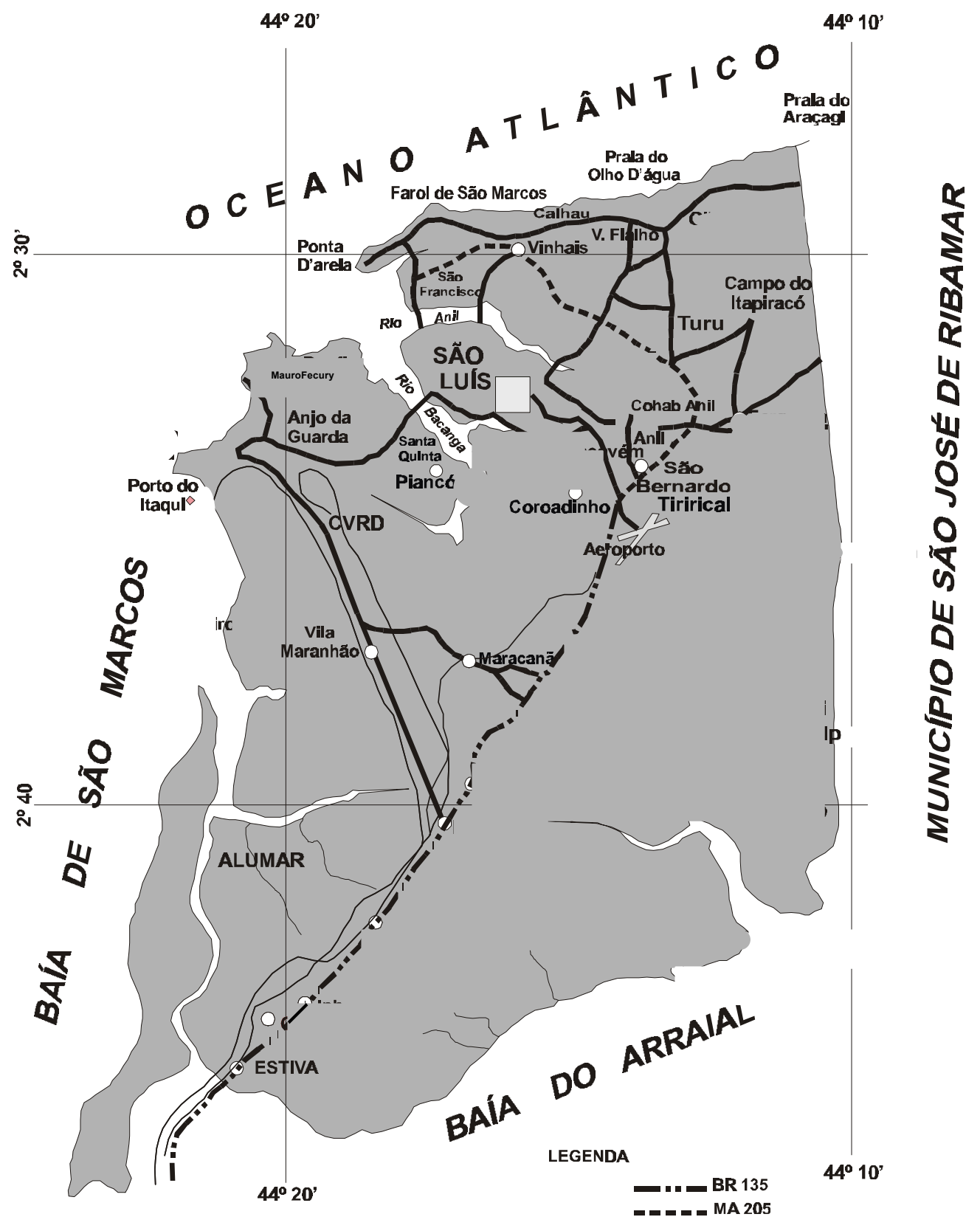

ESCALA: 1: 250.000

Figura 1 - Mapa da Ilha de São Luís com as principais localidades que notificaram LVA no período de setembro de 1982 a dezembro de 1996. 


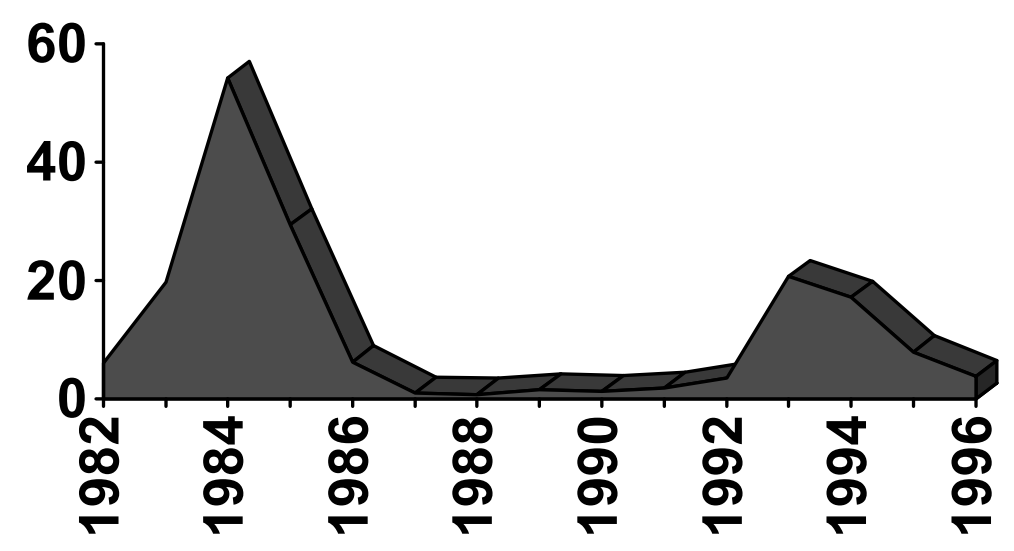

Figura 2 - Coeficiente de incidência de calazar por 100 mil habitantes em São Luis, 1982-1996.

\section{DISCUSSÃO}

A expansão da LVA em São Luis partiu do bairro do Tirirical, seguiu o sentido da rodovia MA-205, deslocando-se no sentido norte da ilha, em direção ao litoral, numa época em que havia uma grande corrente migratória que fluía para este setor da cidade, vinda principalmente da área rural da cidade. Este eixo de expansão do calazar se delineou desde os primeiros instantes da epidemia. A partir de 1984 a expansão da LVA dirigiu-se ao centro da cidade, mantendo número de casos, inferior ao eixo que se deslocava para o norte da ilha. A partir do centro a expansão se estendeu para o bairro do Anjo da Guarda que recebia, de forma desordenada e sem estrutura de serviços básicos, a população que era deslocada da área destinada à CVRD e posteriormente da área destinada à ALUMAR. Neste período observou-se que, a área ocupada pela CVRD não apresentou nenhum caso de calazar notificado, enquanto que no bairro do Anjo da Guarda, principal receptor da população deslocada da área destinada para aquela companhia, a epidemia grassou fortemente tendo sido um dos bairros com o maior número absoluto de casos notificados.

Observou-se que por muitos anos o crescimento populacional voltado para o sul da ilha esteve limitado em parte pela presença física do Distrito Industrial implantado nessa área e, em parte, pelo vazio populacional desse setor determinado pelo deslocamento de milhares de lavradores com suas famílias quando da implantação do referido distrito. Várias localidades que notificaram calazar nessa época surgiram entre 1991 e 1994 como áreas receptoras de migrantes.

No início da década de 1990, o litoral da cidade encontrava-se com grande adensamento demográfico provocado pela classe média e alta que aí se estabeleceu, não sobrando terras livres para serem ocupadas. Assim a expansão urbana seguiu no sentido nordeste em direção aos municípios de São José de Ribamar e Paço do Lumiar, onde surgem conjuntos habitacionais bem estruturados, e em direção às áreas rurais ao sul e leste da ilha. A expansão no sentido sul era facilitada pelas grandes faixas de terra disponíveis neste setor, as quais se estendiam até o município de Estiva no extremo sul da ilha, servidas pela BR-135. O setor leste, que possuía muitas terras desocupadas servidas por grande rede de estradas vicinais, também recebeu importante fluxo migratório nesse período.

\section{REFERÊNCIAS BIBLIOGRÁFICAS}

1. Araújo A, Chame M, Pessis AM, Souza SMFM, Ferreira LF. A ocupação do espaço: da pré-história aos dias atuais. In: SAUDE, Ambiente e Desenvolvimento: Uma análise interdisciplinar. Hucitec/ABRASCO 1: 181-194, 1992.

2. Barreto MP. movimentos migratórios e sua importância na epidemiologia de doenças infecciosas e parasitárias no Brasil. Revista da Sociedade Brasileira de Medicina Tropical 1: 91-102, 1967.

3. Costa JML, Viana GMC, Saldanha ACR, Nascimento MDSB, Alvim AC, Burattini MN, Silva AR. Leishmaniose visceral no Estado do Maranhão: a evolução de uma epidemia. Cadernos de Saúde Pública 11: 321-324, 1995.
4. Ferreira AJA. A urbanização e a problemática ambiental em São Luís. Monografia apresentada ao Curso de Especialização em Geografia Aplicada ao Planejamento Ambiental. São Luís, Universidade Federal do Maranhão, 1993.

5. Freitas O. Doenças Africanas no Brasil. São Paulo: Nacional, 1935.

6. Fundação Instituto Brasileiro de Geografia e Estatística. Censo Demográfico. Maranhão. VIII Recenseamento Geral do Brasil 1970, 1971.

7. Fundação Instituto Brasileiro de Geografia e Estatística. Censo Demográfico. Maranhão. IX Recenseamento Geral do Brasil 1980, 1981. 
8. Pastore J. Brasília: a Cidade e o Homem. Uma investigação sociológica sobre o processo de migração, adaptação e planejamento urbano. São Paulo: Nacional/Editora da Universidade de São Paulo, 1969.

9. Sabrosa PC, Toledo LM, Osanai CH. A organização do espaço e os processos endêmico-epidêmicos. In: Saúde, Ambiente e Desenvolvimento: processos e consequências sobre as condições de vida 2: 57-77, 1992.

10. Secretaria de Planejamento. Perfil do aglomerado urbano da llha de São Luís-MA. SEPLAN-MA, 1983.
11. Silva AR, Viana GMC, Varonil C, Pires B, Nascimento MDSD, Costa JML. Leishmaniose visceral (calazar) na llha de São Luís, Maranhão, Brasil: evolução e perspectivas. Revista da Sociedade Brasileira de Medicina Tropical 30: 359-368, 1997.

12. Trovão JR. Transformações sociais e econômicas no espaço rural da Ilha do Maranhão. Tese de Doutorado, Universidade Estadual Paulista, Rio Claro(SP), 1994. 